\section{PROGRESS AND ETHICS}

\section{The Sociology of Progress}

By Leslie Sklair. (International Library of Sociology and Social Reconstruction.) Pp. xvi +272 . (Routledge and Kegan Paul: London, November 1970.) 65s.

THIs book falls into two parts. The first, consisting of a brief history of the idea of progress, is competently enough done, but neither very original nor very profound. It serves chiefly as a setting for the more important second part, which is intended to establish, rather grandiloquently, "the" sociology of progress.

Here we start at once with the difficulty of definition. This is more than a verbal problem, for whereas for most other people working in the field progress means an immanent tendency for the system to "improve" in some sense to be defined, here it seems to be derived from an individualist basis, the desire of every human being for things to get better with him and to have his problems solved. This, of course, begs all the questions, such as the distinction between people's desire for progress and its actual historical experience, the success and effectiveness with which people pursue "progress" as against other aims, and the common situation in which the quest for "progress" by one group can be achieved only at the cost of regression by others. Indeed, because he maintains that all historical ideas are ideas of progress, and all history is the history of progress, certainly so in the case of knowledge and "probably" so in the case of social progress, it seems that the author has never considered the opposite, that is, regression, and the desire of powerful segments of all societies to turn back the clock. It is left to a footnote to make the proviso that "there have of course been periods in history when knowledge has stood still or has even been lost, but the general trend has been cumulative and progressive. I am speaking, of course, about the Western world", thus admitting that the sociology of progress is valid for only a small fraction of the historical experience, and not wholly valid even there.

The main claim to originality made in the book is the distinction between innovational and non-innovational progress. The discussion of this distinction which is intended to be central to the argument, makes heavy weather of it without advancing much beyond the Schumpeterian distinction between a now idea and its general acceptance, and ends up rather lamely with the admission that these two concepts are "ends of a continuum rather than twins in a dichotomy". The distinction between them is used for at least two major purposes. One is to show that non-innovational progress is progress of a kind, especially in the moral sphere, for example, the creation of a "better" society, nearer to an ideal that might well be an old-established one. The other is to claim that since the "institutionalization of science", which is here placed around the year 1800 , the West has increasingly and mistakenly looked for, and worked for, the "innovational" kind of progress only.

Even if this concept is the most original, there is another which is more central to the argument. That is what is called the "sociological ethic", that is, the conversion of sociology into a normative science. One's sym. pathies are with anybody operating in this particular area where angels fear to tread; here the ethical criterion adopted is that of "meeting the needs" or "solving" the problem of individuals and societies: any society improving its performance in either of these two respects is, by definition, progressive. This, then, is the solution offered to all those who in the past have been sure of scientific and perhaps even economic progress, but never about moral progress. We can make statements about the moral progress of human society, and sociology can make value judgments, and the two are linked. Although the title of the book is about the former, one suspects that the author is more interested in the latter. Several value judgments are attempted on particular recent issues, such as the vast expenditure on the space programme at a time of widespread human poverty and disease, or the "biological time bomb", the tampering with genetic factors. On these, and other matters, the author has interesting, even if not original, things to say, but it is hard to see how "the" sociology of progress has helped him towards his views.

There are some glaring omissions in this approach, notably the a-historical attitude, in spite of some mention of relativism, and the failure to note the existence of classes and other opposed interest groups, whose "needs" and "problems" might conflict:- and then whose needs should have priority in the name of "progress"? There are also too many loose ends in the internal structure of the argument and the claims are consistently pitched too high, even in the title. But Mr Sklair is able to deal in an intelligent way with a number of the most urgent current problems, including the uses and abuses of science; and he deserves high marks for effort in introducing ethics into sociology. Sidney Pollard

\section{HAPPY BIRTHDAY NRDC}

\section{Project $X$}

The Exciting Story of British Invention. By Peter Fairley. Pp. $239+8$ plates. (Mayflower: London, October 1970. $7 s$ paper.

THe idea that Britain is uniquely bad at turning her inventions into new products is a persistent theme in Parliament and elsewhere. It is, in fact, a myth-fed by a lack of objective information and dependent on the Protestant view that inventiveness is a moral virtue not far short of godliness and cleanliness. In reality, almost all the important twentieth century technologies found their origins elsewhere; the motor car in France and Germany, the aeroplane in France and the United States, computers in the United States and Germany, electronics almost everywhere.

It is necessary to risk labouring this point because it was with the intention of remedying Britain's alleged weaknesses that the National Research Development Corporation was set up, and whose twenty-first birthday now provides a pretext for publishing this book. It opens with a wonderfully characteristic foreword by $\mathrm{Mr}$ Harold Wilson: "It is perhaps right that I should recall the opening words with which I commended the Second Reading of the Development of Inventions Bill to the House of Commons ... the whole world will agree that this country has been second to none in the production of new ideas and of new inventions. But in the past we have sometimes been slow to put these ideas into full use, or even, occasionally, neglectful of them altogether, often with very grave results".

The history of NRDC since then should have laid such arguments to rest for ever. For all its success, it has handled very few inventions of the first rank. Only the hovercraft and the cephalosporin drugs qualify even for the middle rank in terms of economic impact or pecuniary return. Where, the curious might inquire, were all the major inventions which would otherwise have gone unexploited or abroad? The truth is that there weren't any. In spite of this, the illusions persist-proving once again that myth has a much greater hold on the public imagination than reality.

But what of the book? Peter Fairley is a science popularizer of the old school, somewhat overfond of a "gee-whizz" style of delivery. It is a style acceptable, even necessary, over the short course of half-column pieces in an evening newspaper, but it becomes trying over the long haul of a fattish paperback. Fairley does not shrink from quoting at length pieces originally published 